\title{
Evaluating potential olive orchard sugar food sources for the olive fly parasitoid Psyttalia concolor
}

\author{
C. Furtado - A. F. Belo • F. M. Nunes • E. Ganhão • \\ C. T. Müller $\cdot$ L. Torres $\cdot$ F. T. Rei
}

Received: 5 May 2015/ Accepted: 16 March 2016

(C) International Organization for Biological Control (IOBC) 2016

\begin{abstract}
Olive fruit fly Bactrocera oleae (Rossi) (Diptera: Tephritidae) is a major olive pest in the Mediterranean basin where increasing insecticide resistance has enhanced damage and necessitates more reliance on other control strategies, such as biological control. Provision of floral resources has been reported to improve the effectiveness of natural enemies. Here, we tested the effect of six plant nectars and two honeydew sources on the survival of Psyttalia concolor (Szépligeti) (Hymenoptera: Braconidae), a parasitoid wasp used in the biological control of olive fruit fly. Our results showed a positive effect on survival associated with nectars of Anchusa azurea Mill., Rosmarinus officinalis L., Lavatera cretica L. and Calamintha nepeta (L.) Savi, while honeydew
\end{abstract}

Handling Editor: Stefano Colazza

Electronic supplementary material The online version of this article (doi:10.1007/s10526-016-9732-5) contains supplementary material, which is available to authorized users.

C. Furtado · A. F. Belo · E. Ganhão · F. T. Rei ( $₫)$ ICAAM - Instituto de Ciências Agrárias e Ambientais Mediterrânicas, Instituto de Investigação e Formação Avançada, Escola de Ciência e Tecnologia, Universidade de Évora, Núcleo da Mitra, Ap. 94, 7002-554 Évora, Portugal

e-mail: frei@uevora.pt

F. M. Nunes

CQ-VR, Centro de Química. Departamento de Química, Universidade de Trás-os-Montes e AltDouro,

5001-801 Vila Real, Portugal proved to be a valuable alternative food source. When offering flowers directly to insects, Anchusa azurea, Lavatera cretica, and Foeniculum vulgare L. were found to be the most beneficial species, indicating also that $P$. concolor feeds predominantly on shallow corollas.

Keywords Hymenoptera: Braconidae · Nectar · Honeydew $\cdot$ Survival $\cdot$ Conservation biological control

\section{Introduction}

The olive fruit fly, Bactrocera oleae (Rossi) (Diptera: Tephritidae), is considered one of the most damaging olive pests in the Mediterranean basin (Tzanakakis 2003), and causes losses as high as $98 \%$ of a harvest, resulting into average losses exceeding one billion dollars per year (Bueno and Jones 2002). The fly has

C. T. Müller

Organisms \& Environment Division School of Biosciences, College of Biomedical \& Life Sciences, Cardiff University, The Sir Martin Evans Building, Museum Avenue, Cardiff CF10 3AX, UK

L. Torres

CITAB, Centro de Investigação e de Tecnologias AgroAmbientais e Biológicas, Universidade de Trás-os-Montes e Alto Douro, 5001-801 Vila Real, Portugal 